\title{
The Corrosion Behavior of Amorphous and Crystalline Ni-Cr-Metalloid Alloys
}

\author{
Bo-Ping Zhang*, Asahi Kawashima*, Katsuhiko Asami* and Koji Hashimoto* \\ * Institute for Materials Research, Tohoku University
}

\begin{abstract}
The corrosion behavior of $\mathrm{Ni}-\mathrm{Cr}-\mathrm{P}-\mathrm{C}$ alloys in which the $\mathrm{Ni} / \mathrm{Cr}$ atomic ratio was fixed to unity was studied in connection with metallurgical structure by electrochemical measurement and X-ray diffraction. The $\mathrm{Ni}-\mathrm{Cr}$ alloy was vitrifiable by the addition of 12 at $\%$ phosphorus, but was not by single addition of carbon. In $6 \mathrm{~N} \mathrm{HCl}$ at $30^{\circ} \mathrm{C}$, both conventionally cast and melt-spun crystalline $\mathrm{Ni}-\mathrm{Cr}$ alloys had low corrosion potentials less than $-300 \mathrm{mV}$ (SCE) and showed high anodic current density of the order of $10^{3}$ to $10^{4} \mathrm{~A} / \mathrm{m}^{2}$ by anodic polarization. Once they were vitrified, they passivated spontaneously in the same aggressive solution and showed excellent corrosion resistance. The corrosion resistance of amorphous alloys was largely deteriorated even by a small amount of crystalline phase precipitation.
\end{abstract}

Key words: amorphous alloy, $\mathrm{Ni}-\mathrm{Cr}$ alloy, vitrifiability, effect of metalloid elements, corrosion resistance, crystalline phase

\section{Introduction}

Chromium is one of the most effective alloying elements to improve the corrosion resistance of amorphous and conventional crystalline alloys. According to XPS studies, chromium provides a high protective quality of the passive film due to enrichment in the film in the form of hydrated chromium oxyhydroxide ${ }^{1) \sim 9)}$. Metalloid elements constituting amorphous metalmetalloid alloys have been known to affect the corrosion behavior ${ }^{10) \sim 12)}$. Among phosphorus, silicon, boron and carbon, a combined addition of phosphorus and carbon is most effective in improving the corrosion resistance in non-oxidizing environments such as $\mathrm{NaCl}$ and $\mathrm{HCl}$ solutions. It is expected that, as far as a single phase alloy is formed, the higher the chromium content, the higher is the corrosion resistance. However, unless the amorphous structure is formed, the addition of a large amount of chromium leads inevitably to the formation of multiple phase alloy, which is undesirable from various points of view including the corrosion resistance. On the other hand, the addition of metalloids may be effective to form the amorphous structure even if the chromium content is very high.

\footnotetext{
* 2-1-1, Katahira, Sendai, 980 Japan
}

In the present work, as the extreme case of the high chromium content, the $\mathrm{Ni}-\mathrm{Cr}$ alloys whose atomic ratio of the nickel to chromium is unity are chosen, and the effect of the change in the structure of melt-spun alloys with additions of phosphorus and carbon on the corrosion behavior has been investigated.

\section{Experimental}

Various kinds of alloy ingots were prepared by high frequency induction melting of commercial electrolytic nickel, electrolytic chromium, chromium carbide ( $\mathrm{Cr}-9.9 \mathrm{wt} \% \mathrm{C}$ ), and nickel phosphide $(\mathrm{Ni}-14 \mathrm{wt} \% \mathrm{P})$ in an argon atmosphere. The atomic ratio of nickel to chromium was fixed to $1: 1$ all through the experiment. Hereinafter $\mathrm{Ni}-\mathrm{Cr}(1: 1)$ refers to this alloy system and the compositions are given in atomic \% (at $\%)$. These alloy ingots are called mother alloys. Then, mother alloys were remelted and rapidly solidified using a melt-spinning apparatus with a copper roller of $300 \mathrm{~mm}$ in diameter, the rotating speed being about $2500 \mathrm{rpm}$. By this method, rapidly quenched alloy ribbons of about $0.5-1.0 \mathrm{~mm}$ wide and $10-30 \mu \mathrm{m}$ thick were obtained. The structures of rapidly quenched alloys and mother alloys were confirmed by X-ray diffraction. Potentiodynamic polarization curves of the as-prepared alloy rib- 
bons were measured in $6 \mathrm{~N} \mathrm{HCl}$ solution at $30^{\circ} \mathrm{C}$ with a potential sweep rate of $1.79 \mathrm{mV} / \mathrm{sec}$. Potentials were measured against the saturated calomel electrode (SCE).

\section{Results and Discussion}

The X-ray diffraction patterns of the $\mathrm{Ni}-\mathrm{Cr}$ $(1: 1)-13.5 \mathrm{C}$ mother alloy and the rapidly quenched counterpart are presented in Fig. 1. Both specimens show almost the same diffraction patterns, which are assigned to a mixture of an fcc Ni-Cr-C phase and $\mathrm{Cr}_{7} \mathrm{C}_{3}$ compound. Rapid quenching results in an increase in peak heights of the fcc phase, such as (111) and (200). It is difficult to estimate the concentrations of fcc phase and $\mathrm{Cr}_{7} \mathrm{C}_{3}$ compound in these alloys because fcc (111), (200) and (220) lines are overlapped with the lines of $\mathrm{Cr}_{7} \mathrm{C}_{3}$ and because intensity ratios among the lines of the same phase well also changed by rapid quenching. However, it can be qualitatively said that the increase in fcc (111) and fcc (200) intensities mentioned above is related to the suppression of carbide precipitation by rapid quenching.

Figure 2 shows the X-ray diffraction results of rapidly quenched alloys containing only phosphorus as the metalloid element. At 10 at $\%$ P, the alloy is completely crystalline, and two crystalline phases, are assigned to fcc Ni-Cr-P and $\mathrm{Cr}_{3} \mathrm{P}$. However, when the phosphorus content

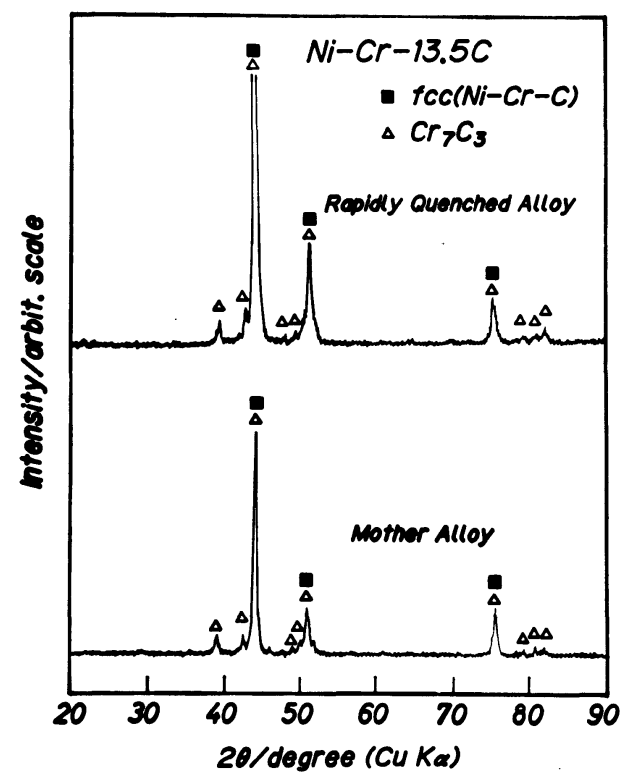

Fig. 1 The X-ray diffraction patterns of $\mathrm{Ni}-\mathrm{Cr}(1$ : 1)-13.5C alloy and rapidly quenched counterpart.

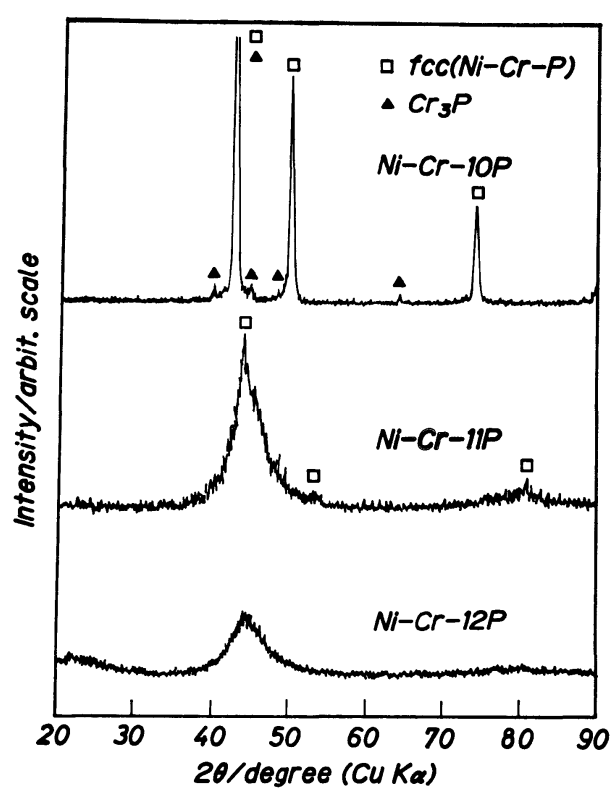

Fig. 2 The X-ray diffraction patterns of rapidly quenched Ni-Cr $(1: 1)-x \mathrm{P}$ alloys with $x=10$, 11 and 12 at $\%$.

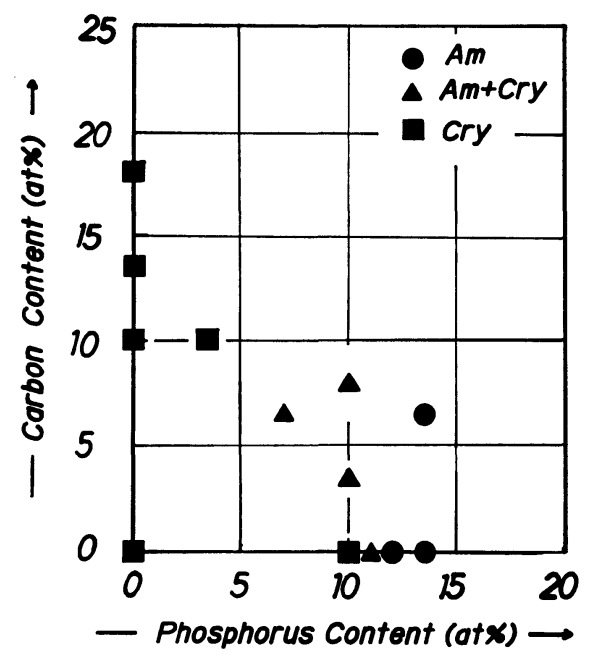

Fig. 3 The structure-composition diagram of the rapidly quenched $\mathrm{Ni}-\mathrm{Cr}(1: 1)-\mathrm{P}-\mathrm{C}$ alloys.

is increased to 11 at $\%$, the major phase becomes amorphous although still small amounts of crystalline phases are included. When the phosphorus content is increased to 12 at $\%$, no crystalline phases are detectable anymore and the diffraction pattern becomes a halo typical of the amorphous structure. Thus the glass forming ability increases with increasing phosphorus content in this phosphorus content range.

The glass forming ability of $\mathrm{Ni}-\mathrm{Cr}(1: 1)$ alloy is largely changed with the metalloid content. 
Table 1 The phases observed by X-ray diffraction for rapidly quenched alloys and their mother alloys.

\begin{tabular}{|c|c|c|}
\hline Alloy System & Mother Alloy & Rapidly Quench Alloy \\
\hline $\mathrm{Ni}-\mathrm{Cr}(1: 1)$ & $\mathrm{fcc}(\mathrm{Ni}-\mathrm{Cr})$ & $\mathrm{fcc}(\mathrm{Ni}-\mathrm{Cr})$ \\
\hline $\begin{array}{l}\mathrm{Ni}-\mathrm{Cr}(1: 1)-\mathrm{P} \\
(\mathrm{P}<11 \text { at } \%)\end{array}$ & \multirow{3}{*}{$\mathrm{fcc}(\mathrm{Ni}-\mathrm{Cr}-\mathrm{P})+\mathrm{Cr}_{3} \mathrm{P}$} & $\mathrm{fcc}(\mathrm{Ni}-\mathrm{Cr}-\mathrm{P})+\mathrm{Cr}_{3} \mathrm{P}$ \\
\hline $\begin{array}{l}N i-C r(1: 1)-P \\
(P=11 \text { at })\end{array}$ & & Amorphous $+f c c(\mathrm{Ni}-\mathrm{Cr}-\mathrm{P})$ \\
\hline $\begin{array}{c}\mathrm{Ni}-\mathrm{Cr}(1: 1)-\mathrm{P} \\
(11 \text { at\% }<\mathrm{P} \leqq 13.5 \text { at\% }\end{array}$ & & Amorphous \\
\hline $\mathrm{Ni}-\mathrm{Cr}(1: 1)-\mathrm{C}$ & $\mathrm{fcc}(\mathrm{Ni}-\mathrm{Cr}-\mathrm{C})+\mathrm{Cr}_{7} \mathrm{C}_{3}$ & $\mathrm{fcc}(\mathrm{Ni}-\mathrm{Cr}-\mathrm{C})+\mathrm{Cr}_{7} \mathrm{C}_{3}$ \\
\hline
\end{tabular}

The structure-composition diagram of the rapidly quenched $\mathrm{Ni}-\mathrm{Cr}(1: 1)$ alloys containing phosphorus and/or carbon is shown in Fig. 3. Vitrification is difficult by the single addition of carbon as the metalloid element in the composition range examined. Moreover, with increasing carbon content, the rapidly quenched alloy ribbons tend to be brittle. On the other hand, the sole addition of phosphorus is able to make the $\mathrm{Ni}-\mathrm{Cr}(1: 1)$ alloy vitrifiable. In this case, at least 12 at $\%$ phosphorus addition is required for vitrification of the $\mathrm{Ni}-\mathrm{Cr}(1: 1)$ alloy. However, the carbon addition to $\mathrm{Ni}-\mathrm{Cr}(1: 1)-10 \mathrm{P}$ alloy up to 8 at $\%$ carbon does not lead to complete vitrification. Therefore, it can be said that the addition of carbon is much less effective than the phosphorus addition for vitrification in this alloy system. The phases of rapidly quenched alloys containing only phosphorus or carbon as the metalloid element observed by X-ray diffraction are shown in Table 1 , in comparison with those of the mother alloys. In case of alloys containing both phosphorus and carbon, mother alloys consisted of fcc phase and carbides such as $\mathrm{Cr}_{7} \mathrm{C}_{3}$ and $\mathrm{Cr}_{3} \mathrm{C}_{2}$ and $(\mathrm{Cr}, \mathrm{Ni})_{3}$ P-type phosphide. When the phosphorus content was 13.5 at $\%$, the Ni-Cr(1:1)-P-C alloy became amorphorus. Other melt-spun quaternary alloys contained similar phases to those of their mother alloys when they were not completely vitrified.

Fig. 4 shows potentiodynamic anodic polarization curves of $\mathrm{Ni}-\mathrm{Cr}(1: 1)-13.5 \mathrm{C}$ mother alloy and rapidly quenched counterpart measured in $6 \mathrm{~N} \mathrm{HCl}$ at $30^{\circ} \mathrm{C}$. As shown in Fig. 1, both alloys are crystalline and their X-ray diffraction patterns exhibit that both alloys consist of fcc and $\mathrm{Cr}_{7} \mathrm{C}_{3}$ phases although the content of the

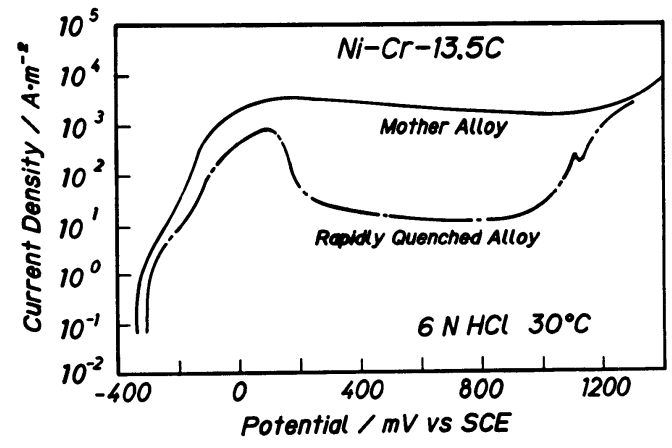

Fig. 4 Anodic polarization curves of Ni-Cr-13.5C mother alloy and rapidly quenched counterpart measured potentiodynamically in $6 \mathrm{~N}$ $\mathrm{HCl}$ at $30^{\circ} \mathrm{C}$.

latter phase seems to be decreased by rapid quenching. As can be seen in Fig. 4, these alloys show quite different electrochemical behavior. The corrosion potentials for the mother alloy and rapidly quenched counterpart are $-340 \mathrm{mV}$ and $-300 \mathrm{mV}$, respectively. Up to $100 \mathrm{mV}$, both polarization curves are almost in parallel, the current density for the rapidly quenched one being lower. At $100 \mathrm{mV}$ and higher potentials, the mother alloy keeps very high anodic current density of ca. $3 \times 10^{3} \mathrm{~A} / \mathrm{m}^{2}$. By contrast, the rapidly quenched ribbon specimen passivates at ca. $100 \mathrm{mV}$, though the current density in the passive state is so high as ca. $20 \mathrm{~A} / \mathrm{m}^{2}$. It is reported that rapidly quenched $\mathrm{Ti}-40$ and $61.5 \mathrm{Ni}$ alloys show similar behavior, that is, the mother alloys do not passivate or have very high passive current density while the rapidly quenched counterparts passivate spontaneously in $1 \mathrm{~N} \mathrm{HCl}^{13)}$. In that case, the rapidly quenched alloys were composed of a 


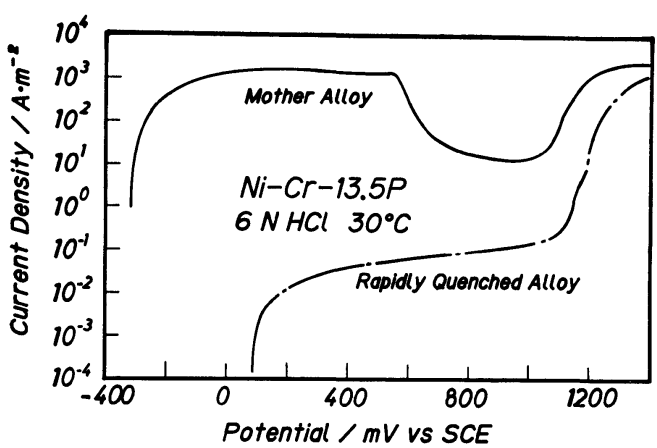

Fig. 5 Anodic polarization curves of $\mathrm{Ni}-\mathrm{Cr}-13.5 \mathrm{P}$ mother alloy and rapidly quenched counterpart measured potentiodynamically in $6 \mathrm{~N}$ $\mathrm{HCl}$ at $30^{\circ} \mathrm{C}$.

crystalline TiNi phase, while the mother alloys consisted of two phase mixtures and the explanation was that, rapid quenching expands the homogeneity range of the $\mathrm{TiNi}$ phase and prevents the formation of chemically heterogeneous sites based on compositional fluctuations. Rapid quenching also highly improved the pitting corrosion resistance of stainless steels $^{14)} \mathrm{Al}$ alloys ${ }^{15), 16)}$, and $\mathrm{Fe}-\mathrm{Cr}$ alloys ${ }^{17)}$ by refining the grain-size together with the suppression of precipitates and segregates which will act as corrosion active sites. As mentioned above, the rapid quenching of $\mathrm{Ni}-\mathrm{Cr}-\mathrm{C}$ alloys does not lead to complete elimination of carbide. Consequently, the decrease in portion of carbide phase in the rapidly quenched alloy might be one of the causes of the passivation.

Potentiodynamic anodic polarization curves of $\mathrm{Ni}-\mathrm{Cr}(1: 1)-13.5 \mathrm{P}$ mother alloy and rapidly quenched counterpart measured in the same condition are shown in Fig. 5. As shown in Fig. 3, the latter is amorphous. The mother alloy has a corrosion potential at ca. $-300 \mathrm{mV}$ and exhibits a very high anodic current density of the order of $10^{3} \mathrm{~A} / \mathrm{m}^{2}$ up to ca. $+550 \mathrm{mV}$ where the current density decreases to the order of $10 \mathrm{~A} / \mathrm{m}^{2}$. On the other hand, the amorphous counterpart shows a very high corrosion potential (ca. $+50 \mathrm{mV}$ ) due to spontaneous passivation. Its passive current density ranges from 0.01 to $0.1 \mathrm{~A} / \mathrm{m}^{2}$, and increases gradually with the applied potential. Remarkable increase in corrosion resistance by vitrification is obvious.

Potentiodynamic anodic polarization curves of a series of rapidly quenched $\mathrm{Ni}-\mathrm{Cr}(1: 1)-x \mathrm{P}-$ $y \mathrm{C}$ alloys with different concentrations of $\mathrm{P}$ and $\mathrm{C}$ measured in $6 \mathrm{~N} \mathrm{HCl}$ at $30^{\circ} \mathrm{C}$ are shown in

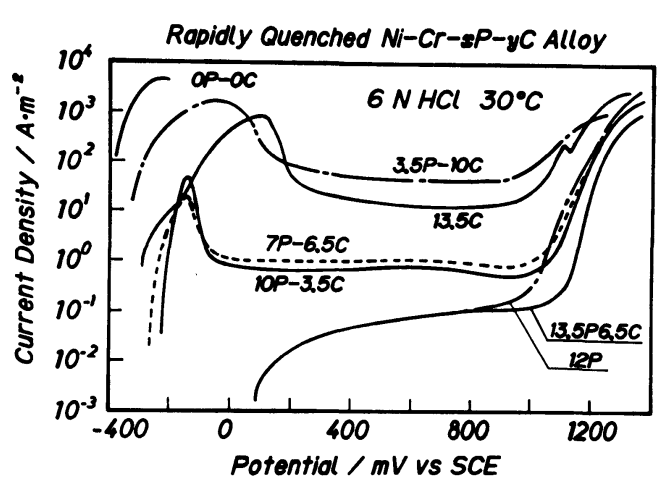

Fig. 6 Anodic polarization curves of a series of representative rapidly quenched $\mathrm{Ni}-\mathrm{Cr}-x \mathrm{P}-$ $y \mathrm{C}$ alloys measured potentiodynamically in $6 \mathrm{~N} \mathrm{HCl}$ at $30^{\circ} \mathrm{C}$.

Fig. 6. The melt-spun ribbon of $\mathrm{Ni}-\mathrm{Cr}(1: 1)$ alloy without metalloid addition shows very low corrosion potential (ca. $-400 \mathrm{mV}$ ) and a large anodic current density corresponding to active dissolution. Actually, the specimen dissolved away immediately after the measurement was started. In Fig. 6, therefore, just available part of the anodic polarization curve is shown. The anodic polarization curve of its mother alloy was also measured. The anodic current density of the mother alloy steeply increased with anodic polarization but the increase was slightly slow compared to that of the rapidly quenched alloy, and was ca. $7 \times 10^{3} \mathrm{~A} / \mathrm{m}^{2}$ between $+100 \mathrm{mV}$ and $+500 \mathrm{mV}$. The current density of the mother alloy suddenly decreased at $+500 \mathrm{mV}$ and passivated with passive current density of $20-60 \mathrm{~A} / \mathrm{m}^{2}$ at potentials higher than $+500 \mathrm{mV}$. At $+1100 \mathrm{mV}$, it showed transpassivation.

The Ni-Cr (1:1) alloys containing $13.5 \mathrm{P}-6.5 \mathrm{C}$ or $12 \mathrm{P}$ were vitrifiable and passivate spontaneously in $6 \mathrm{~N} \mathrm{HCl}$ at $30^{\circ} \mathrm{C}$ when vitrified. The $\mathrm{Ni}-\mathrm{Cr}(1: 1)-7 \mathrm{P}-6.5 \mathrm{C}$ and $\mathrm{Ni}-\mathrm{Cr}(1: 1)-10 \mathrm{P}-3.5 \mathrm{C}$ alloys consisting of major amorphous and small quantity of crystalline phases have the corrosion potential at $-270 \mathrm{mV}$ and $-230 \mathrm{mV}$, respectively, and show the active-passive transition. The passive current densities of these rapidly quenched alloys are ca. $1 \mathrm{~A} / \mathrm{m}^{2}$, which is about one order of magnitude higher than that of the amorphous alloys. Rapidly quenched $\mathrm{Ni}-\mathrm{Cr}$ (1:1)-13.5C and $\mathrm{Ni}-\mathrm{Cr}(1: 1)-3.5 \mathrm{P}-10 \mathrm{C}$ were crystalline and have low corrosion potentials at $-340 \mathrm{mV}$ and $-300 \mathrm{mV}$, respectively. They show the active-passive transition but their pas- 


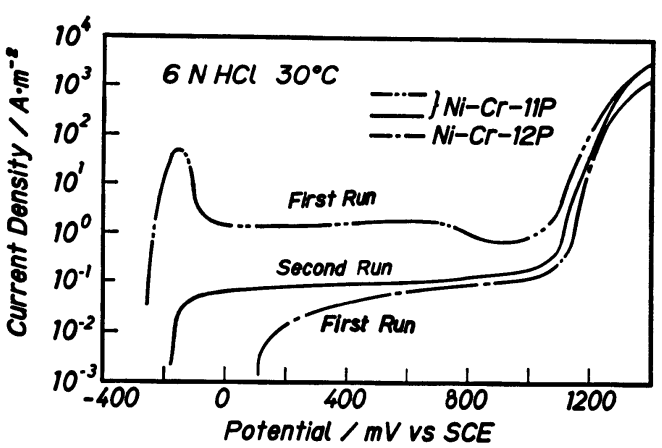

Fig. 7 Comparison between the first and second runs of the anodic polarization measurements for an amorphous $\mathrm{Ni}-\mathrm{Cr}(1: 1)-11 \mathrm{P}$ alloy which in fact contains a small amount of crystalline phases. The included is also the first run of anodic polarization measurement for the amorphous $\mathrm{Ni}-\mathrm{Cr}(1: 1)-12 \mathrm{P}$ alloy.

sive current density are 20 and $60 \mathrm{~A} / \mathrm{m}^{2}$ at minimum, respectively. Thus, it can be said that the corrosion behavior of rapidly quenched alloys is very strongly affected by the structure.

All the polarization curves shown so far are those obtained by a single scan. In order to confirm the effect of the crystalline phases contained in a rapidly solidified alloy on the corrosion behavior, anodic polarization curves of partially crystalline $\mathrm{Ni}-\mathrm{Cr}(1: 1)-11 \mathrm{P}$ alloy were measured twice for the same specimen successively. The results are shown in Fig. 7. The first run of the polarization measurement for the rapidly quenched amorphous $\mathrm{Ni}-\mathrm{Cr}(1: 1)-$ $12 \mathrm{P}$ alloy is also shown for comparison. The difference between the first and the second runs of the Ni-Cr-11P alloy is clear. In the first run, an active region exists, and the passive current density is of the order of $1 \mathrm{~A} / \mathrm{m}^{2}$, while, in the second run, the active peak disappears, and the specimen passivates spontaneously with a low passive current density of almost the same level as that of the amorphous $\mathrm{Ni}-\mathrm{Cr}(1: 1)-$ 12P alloy although their open circuit potentials are different. The difference between the first and second runs could be explained by dissolution of crystalline phases near the surface during the first run. However, even after the dissolution of the surface crystalline phases, the corrosion potential is much lower than that of amorphous $\mathrm{Ni}-\mathrm{Cr}(1: 1)-12 \mathrm{P}$ alloy. This fact suggests that total elimination of crystalline phases in amorphous alloys is very important to obtain high corrosion resistance.

\section{Conclusions}

The relationship between the structure and the electrochemical behavior for $\mathrm{Ni}-\mathrm{Cr}(1: 1)$-metalloid alloys prepared by melt-spinning method are studied. The following conclusions are drawn:

(1) Rapid quenching with melt-spinning method gives rise to different structure depending upon the alloy composition: The $\mathrm{Ni}-\mathrm{Cr}$ $(1: 1)-(10-18) \mathrm{C}$ alloys are crystalline. The Ni$\operatorname{Cr}(1: 1)-x \mathrm{P}$ alloys become amorphous at $x>11$ at $\%$, but are crystalline at $x \leqq 10$ at $\%$, the $\mathrm{Ni}-$ $\mathrm{Cr}(1: 1)-11 \mathrm{P}$ alloy consists mainly of amorphous phase containing a small amount of crystalline phase.

(2) $\mathrm{Ni}-\mathrm{Cr}(1: 1)-12 \mathrm{P}, \quad \mathrm{Ni}-\mathrm{Cr}(1: 1)-13.5 \mathrm{P}$ and $\mathrm{Ni}-\mathrm{Cr}(1: 1)-13.5 \mathrm{P}-6.5 \mathrm{C}$ alloys exhibit a halo $\mathrm{X}$-ray diffraction patterns typical of the amorphous structure, and passivate spontaneously showing an excellent high corrosion resistance in $6 \mathrm{~N} \mathrm{HCl}$ at $30^{\circ} \mathrm{C}$.

(3) The crystalline phases coexisting in the amorphous phase exerts a large detrimental effect upon the corrosion resistance of the alloys.

(Received January 23, 1989)

\section{References}

1) K. Asami, K. Hashimoto, T. Masumoto \& $\mathrm{S}$. Shimodaira: Corros. Sci., 16, 909 (1976).

2) K. Hashimoto, M. Kasaya, K. Asami \& T. Masumoto: Boshoku Gijutsu (Corros. Engng.), 26, 442 (1977).

3) K. Asami, K. Hashimoto \& S. Shimodaira: Corros. Sci., 18, 151 (1978).

4) K. Hashimoto, K. Asami \& K. Teramoto: Corros. Sci., 19, 3 (1979).

5) K. Hashimoto \& K. Asami: Corros. Sci., 19, 251 (1979).

6) K. Hashimoto, K. Asami, M. Naka \& T. Masumoto: Boshoku Gijutsu (Corros. Engng.), 28, 271 (1979).

7) K. Hashimoto \& K. Asami: Corros. Sci., 19, 1007 (1979).

8) K. Hashimoto, K. Kobayashi, K. Asami \& T. Masumoto: in "Metallic Corrosion", Proc. 8th Intrn. Congr. on Metallic Corrosion, Mainz, Fed. Rep. Germany, 1981, DECHEMA, Frankfurt/ Main, Vol. 1, p. 70 (1981).

9) A. Kawashima, K. Asami \& K. Hashimoto: Corros. Sci., 24, 807 (1984).

10) M. Naka, K. Hashimoto \& T. Masumoto: $J$. Non-Cryst. Sol., 28, 403 (1978).

11) K. Hashimoto, M. Naka, K. Asami \& T. Masumoto: Boshoku Gijutsu (Corros. Engng.), 27, 279 (1978). 
12) K. Hashimoto, K. Asami \& A. Kawashima: in Proc. 9th Intrn. Congr. on Metallic Corrosion, Toronto, Canada, 1984, National Research Council of Canada, Ottawa, Vol. 1, p. 208 (1984).

13) M. Naka, K. Asami, K. Hashimoto \& T. Masumoto: in "Titanium '80", Proc. 4th Intrn. Conf. on Titanium, Kyoto, Japan, 1988, 'Science and Technology', Vol. 4 (Ed. H. Kimura \& O. Izumi), The Metallurgical Society of AIME, p. 2677 (1980).
14) T. Tsuru \& R. M. Latanision: J. Electrochem. Soc., 129, 1402 (1982).

15) A. Saito \& R. M. Latanision: in Proc. 9th Intrn. Congr. on Metallic Corrosion, Toronto, Canada, 1984, National Research Council of Canada, Toronto, Vol. 3, p. 122 (1984).

16) H. Yoshioka, S. Yoshida, A. Kawashima, K. Asami \& K. Hashimoto: Corros. Sci., 26, 795 (1986).

17) A. Kawashima \& K. Hashimoto: Corros. Sci., 26, 467 (1986). 